\title{
A decade of TEN: An update on toxic epidermal necrolysis
}

\author{
N Sam Huq MD, Janet Sproat MSc MD FRCSC \\ McMaster University, Hamilton, Ontario
}

NS Huq, J Sproat. A decade of TEN: An update in toxic epidermal necrolysis. Can J Plast Surg 1996;4(3):150-152. A review of the Hamilton experience over a 10-year period, discussing treatment trends, etiology and outcomes is presented.

Key Words: Etiology, Morbidity, Mortality, Treatment, Toxic epidermal necrolysis

Syndrome de Lyell, une décennie : mise à jour sur l'érythrodermie bulleuse avec épidermolyse

RÉSUMÉ : Survol de l'expérience de Hamilton échelonnée sur une période de 10 ans où l'on présente les tendances thérapeutiques, étiologiques et pronostiques.

Toxic epidermal necrolysis (TEN) was first described by Lyell in 1956 (1). It is a rare condition, with 1.2 cases per million per year (2), and is characterized by a diffuse erythematous rash that progresses to desquamation of a large body surface area. Although TEN is in the clinical continuum of erythema multiforme (EM) and Stevens Johnson syndrome (SJS), biopsy shows complete separation of epidermis to dermis, similar to a deep partial thickness burn. It is a very serious condition with a mortality of $20 \%$ to $30 \%$, even with modern treatment (2-6).

The pathophysiology is not well understood, but it does have a strong immunological basis (7-11) and is often considered an adverse drug reaction. Antibiotics, anticonvulsants and nonsteriodal anti-inflammatory drugs are the most commonly implicated causative agents $(6,12)$. Age and total body surface area (TBSA) desquamated are the strongest prognosticators at the onset of TEN (5).

The purpose of this study is to identify trends predictive of morbidity and mortality in TEN and to determine the relationship between treatment and clinical course.

\section{METHODS}

A retrospective chart analysis of all patients who were diagnosed with TEN in Hamilton, Ontario from 1985 to 1994 was done. Patients with EM, SJS, cellulitis or radiation dermatitis were identified and excluded. Inclusion criterion was a histologically proven biopsy or clinical diagnosis agreed upon by a plastic surgeon and/or dermatologist. Information regarding demograpics, causation, disease parameters, complictions and mortality was obtained. Assessment of drug responsibility followed the methods proposed by Roujeau et al (2) for reporting adverse drug reactions. Introduction of a drug less than three weeks before diagnosis was considered 'highly suggestive' of its 
responsibility, while withdrawal of a drug more than three weeks before diagnosis was considered 'incompatible'.

\section{RESULTS}

Among all patients reviewed, 11 cases of TEN were found. The male:female ratio was 5:6, and the mean age was 47.4 years (range three to 84 ). Past medical history revealed one patient with acquired immunodeficiency syndrome (AIDS), one with steroid-dependent chronic obstructive pulmonary disease, one who had received radiation for metastatic brain melanoma, one with chronic renal failure and one with pancytopenia secondary to methotrexate (Table 1). The suspected causative agents are listed in Table 2. Five of the 11 patients claimed to have had a prior adverse drug reaction, which is considerably higher than the $20 \%$ reported in the ambulatory population (13). The mean time from ingestion to onset of symptoms was 12.6 days (range two to 60). Prodrome included fever, malaise or rash. The mean delay from onset of desquamation to diagnosis was 6.0 days (range two to 17). When treatments were compared, the mean time to heal with pigskin allografts and topical antibiotics was 15.4 days compared with an average of 28 days with silver sulfadiazine (SSD).

\section{TABLE 1: Past medical history}

\section{Total 11 patients}

1 Acquired immunodeficiency syndrome

1 Steroid-dependent chronic obstructive lung disease

1 Metastatic melanoma to brain treated with radiation

1 Chronic renal failure

1 Pancytompenia secondary to methotrexate

6 Unremarkable

TABLE 2: Supected causative agents $(n=11)$

$\begin{array}{lr}\text { Drug } & \text { Number } \\ \text { Amoxicillin } & 2 \\ \text { Imipenem } & 1 \\ \text { Phenytoin } & 2 \\ \text { Hydralazine } & 1 \\ \text { Sulfonamide } & 1 \\ \text { Baclofen } & 1 \\ \text { Methotrexate } & 1 \\ \text { Trazodone } & 1 \\ \text { Vancomycin } & 1\end{array}$


Systemic complications were directly proportional to TBSA desquamated $(\mathrm{P}<0.005)$. Only those with a TBSA greater than $70 \%$ experienced any systemic complications (Figure 1). Common complications found in this study included sepsis, pneumonia, hypovolemia/prerenal azotemia, electrolyte disturbance and liver dysfunction, all in keeping those reported in the literature $(12,14,15)$.

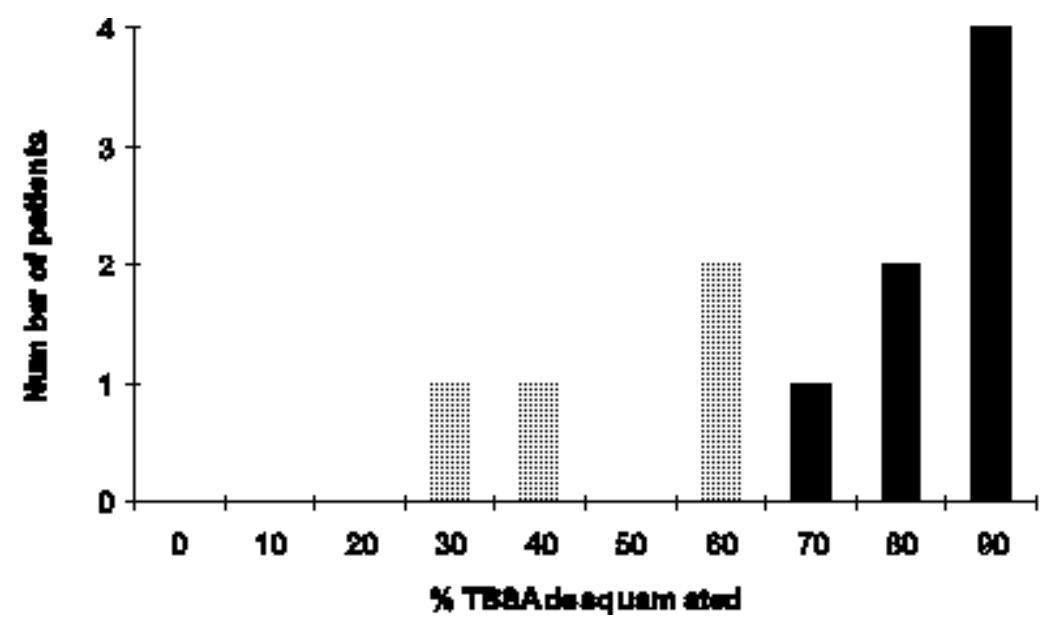

Figure 1) Percentage total body surface area (TBSA) desquamated and systemic complications. Gray indicates no complication; black indicates complications

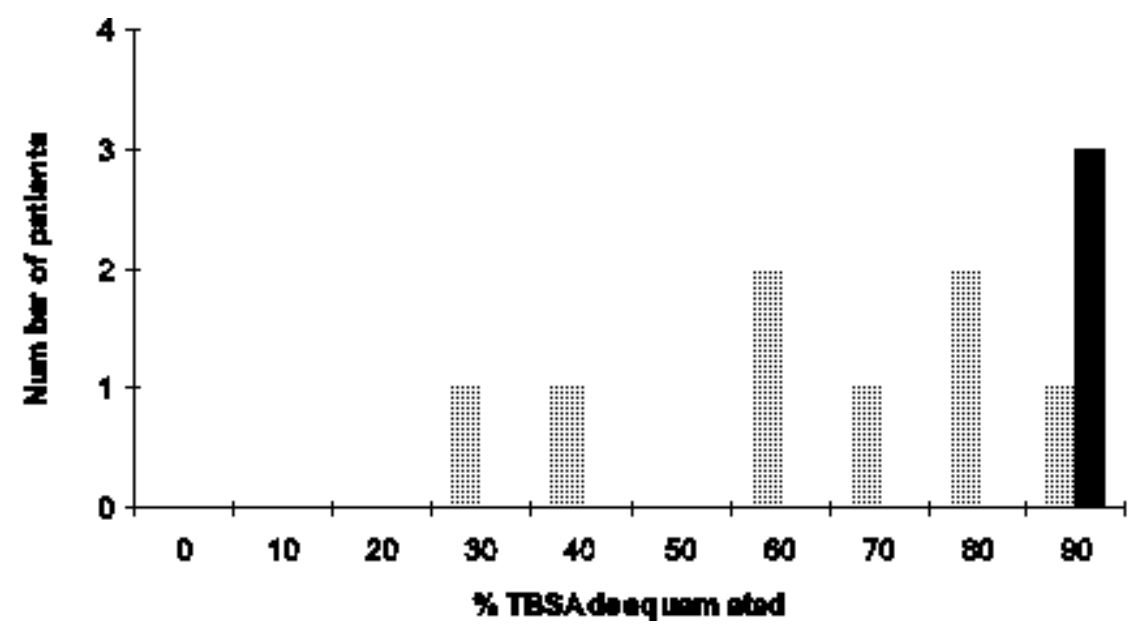

Figure 2) Percentage total body surface area (TBSA) desquamated and mortality. Gray indicates survival; black indicates death 


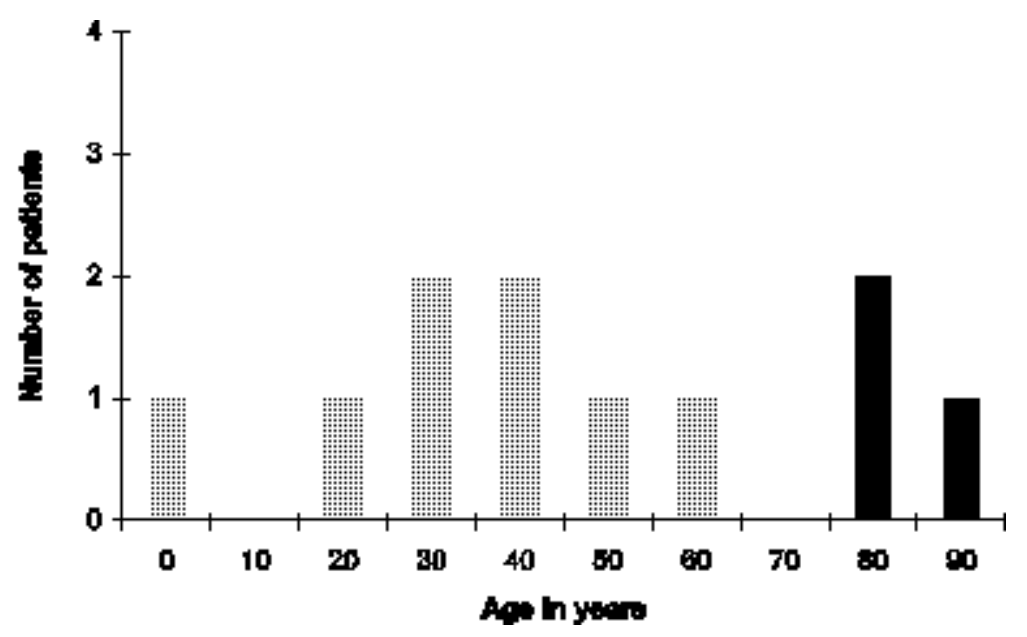

Figure 3) Age and mortality. Gray indicates survival; black indicates death

In addition, mortality was strongly associated with a large surface area of desquamation. The three patients who died desquamated over $90 \%$ of their TBSA (Figure 2). This correlation was statistically significant using a two-tailed probability with separate variance $(\mathrm{P}<0.005)$. Furthermore, only older patients died from the disease (Figure 3). Hence, mortality correlated with age $(\mathrm{P}<0.01)$. The literature reports these factors as prognosticators in TEN (5).

Three of eight survivors had significant pigment changes after three months of follow-up. Sicca syndrome was noted in one of the survivors. Multisystem organ failure secondary to sepsis accounted for the three deaths. The patient with AIDS died as a result of starvation by choice, after recovering from TEN and, thus, was considered a survivor for the purposes of this study.

\section{DISCUSSION}

It must be clearly recognized that most of the data can only be interpreted as trends, not statistically significant conclusions, because of insufficient numbers of patients with the disease. The symptoms and duration of the prodrome are in keeping with the literature. The delay from symptoms to time of diagnosis was likely due to a general unfamiliarity with the disease, because it is quite rare and frequently diagnosis is not made until after a dermatology or plastic surgery consultation occurs.

It is often difficult to establish a simple precipitating factor, chiefly because patients frequently have medications changed and may be taking many causative agents before the onset of symptoms. In a report of 87 cases (6), patients were taking an average of 4.4 drugs each, and a culpable drug was determined in $77 \%$ of patients. Imipenem, trazodone, baclofen and hydralazine have not previously been implicated as etiological agents in TEN; however, we now report this possibility. Because patients on imipenem and hydralyzine were exposed to other known causative drugs, these agents can only be weakly associated with TEN. However, those on trazodone and baclofen had no other drug exposure within three weeks before onset of symptoms. Reports of these cases have been submitted separately (16). 
Other parameters in the disease process are of interest to those who treat TEN. The use of corticosteroids has largely been discouraged $(3,17)$, because there is no beneficial effect once desquamation has begun, generally the time the diagnosis is made. For wound treatment, centres now recommend pigskin allografts and topical antibiotics. SSD has been discouraged since the mid-1980s because it contains sulfa, a known etiological agent; it may delay epithelialization and may induce neutropenia $(4,17)$.

Some conditions, such as AIDS (18-20), systemic lupus erythematosus, leukemia, lymphoma, inflammatory bowel disease and treatment of brain tumors (14), are associated with TEN. It is unclear whether it is the disease process or the associated medications that predispose patients to TEN. Five of the 11 patients were immunocompromised in some way which is in keeping with the suspected immunological etiology (Table 2). Similarly, a history of a previous adverse drug reaction likely has the same immunological basis. Immunocytochemical and electron microscopy findings suggest specific phenotypic characteristics of T lymphocytes which target keratinocytes for cytolysis $(8,10)$. A genetic susceptibility linked to the major histocompatibility complex has been established (21).

At follow-up survivors had few and relatively minor long term sequellae despite the condition's high mortality. Prevalence of pigment changes and Sicca syndrome is in keeping with the literature (17). The most common cause of death reported is sepsis $(3,5)$ as this study found; other causes of death include massive gastrointestinal bleeding or pulmonary embolism, if a cause is actually found. In terms of new treatments, plasmapheresis has shown some promise (17), as well as hyperbaric oxygen (22); however, the few reported cases offer insufficient evidence to pass judgement.

\section{CONCLUSIONS}

TEN patients in this study took less time to heal with xenografts and topical antibiotics compared with SSD. There is a trend towards a higher prevalence of previous adverse drug reactions in the TEN population compared with the ambulatory population. The relatively older patients with TEN have a worse prognosis. The TBSA desquamated is directly proportional to the prevalence of complications as well as mortality.

\section{REFERENCES}

1. Lyell A. Toxic epidermal necrolysis: an eruption resembling scalding of the skin. Br J Dermatol 1956;68:355-61.

2. Roujeau J-C, Guillaume J-C, Fabre J-P, et al. Toxic epidermal necrolysis (Lyell syndrome): Incidence and drug etiology in France, 1981-1985. Arch Dermatol 1990;126:37-42.

3. Halebian PH, Madden MR, Finklestein JL, et al. Improved burn center survival of patients with toxic epidermal necrolysis managed without corticosteroids. Ann Surg 1986;204:503-12.

4. Heimbach DM, Loren LH, Marvin JA, et al. Toxic epidermal necrolysis: A step forward in treatment. JAMA 1987;257:2171-5. 
5. Revuz J, Penso D, Roujeau J-C, et al. Toxic epidermal necrolysis: Clinical findings and prognosis factors in 87 patients. Arch Dermatol 1987;123:1160-5.

6. Guillaume J-C, Roujeau J-C, Revuz J, et al. The culprit drugs in 87 cases of toxic epidermal necrolysis (Lyell's syndrome). Arch Dermatol 1987;123:1166-70.

7. Bagot M, Charue D, Heslan M, et al. Impaired antigen presentation in toxic epidermal necrolysis. Arch Dermatol 1993;129:721-7.

8. Correia O, Delgado L, Ramos JP, et al. Cutaneous T-cell recruitment in toxic epidermal necrolysis: further evidence of CD8+ lymphocyte involvement. Arch Dermatol 1993;129:466-8.

9. Hagdrup H, Tonnesen E, Clemmensen O, et al. Abnormalities

of lymphocyte function and phenotypic pattern in a case of toxic epidermal necrolysis.

Acta Derm Venereol (Stockh)

1992;72:268-70.

10. Heng MCY, Allen SG. Efficacy of cyclophosphamide in toxic epidermal necrolysis: Clinical and pathophysiologic aspects.

J Am Acad Dermatol 1991;25:778-86.

11. Villada G, Roujeau J-C, Clerici T, et al. Immunopathology of toxic epidermal necrolysis: Keratinocytes, HLA-DR expression, Langerhans cells, and mononuclear cells: An immunopathologic study of five cases. Arch Dermatol 1992;128:50-3.

12. Avakian R, Flowers FP, Araujo OE, et al. Toxic epidermal necrolysis: A review. J Am Acad Dermatol 1991;25:69-79.

13. Davies DM. Textbook of Adverse Drug Reactions, 3rd edn. New York: Oxford University Press, 1985.

14. Roujeau J-C, Chosidow O, Saiag P, et al. Toxic epidermal necrolysis (Lyell syndrome). J Am Acad Dermatol 1990;23:1039-58.

15. Tegelberg-Stassen MJAM, van Vloten WA, Baart de la Faille H. Management of nonstaphylococcal toxic epidermal necrolysis: Follow-up study of 16 case histories. Dermatologica 1990;180:124-9.

16. Huq NS, Sproat JE. Baclofen and trazodone: New culprits in toxic epidermal necrolysis. Can J Plast Surg 1996;4:123-124.

17. Revuz J, Roujeau J-C, Guillaume J-C, et al. Treatment of toxic epidermal necrolysis: Creteil's experience. Arch Dermatol 1987;123:1156-8.

18. Rzany B, Hamouda O, Schopf E, et al. Incidence of Stevens-Johnson syndrome and toxic epidermal necrolysis in patients with acquired immunodeficiency syndrome in Germany. Arch Dermatol 1993;129:1059.

19. Saiag P, Caumes E, Chosidow O, et al. Drug-induced toxic epidermal necrolysis (Lyell syndrome) in patients infected with the human immunodeficiency virus. J Am Acad Dermatol 1992;26:567-74.

20. Porteous DM, Berger TG. Severe cutaneous reactions (Stevens-Johnson syndrome and toxic epidermal necrolysis) in human immunodeficiency virus infection. Arch Dermatol 1991;127:740-1.

21. Roujeau J-C, Huynh TN, Bracq C, et al. Genetic susceptibility to toxic epidermal necrolysis. Arch Dermatol 1987;123:1171-3.

22. Ruocco V, Bimonte D, Luongo C, et al. Hyperbaric oxygen treatment of toxic epidermal necrolysis. Cutis 1986;38:267-71. 